\title{
In Defence of Working Papers
}

Scott Timcke

School of Communication, Simon Fraser University

Graeme Webb

School of Communication, Simon Fraser University

Jay McKinnon

School of Communication, Simon Fraser University

Sibo Chen

School of Communication, Simon Fraser University

\begin{abstract}
Working papers are academic articles in various stages of completion, which represents a significant publication venue in various academic disciplines. Nonetheless, there have been considerable amount of critiques on working paper in recent years, especially on its quality and conflict with formal publications. Given the above situation, this article offers a defence of the academic values of working papers. After outlining and addressing common misunderstandings of working papers, the article discusses their four major benefits: the provision of valuable feedback on interim findings, the potential for collaboration, flexible means of dissemination, and the value for intellectual development and capacity building (especially for graduate students). Overall, these benefits underscore a commitment to open-access research that is accessible to the public at large.
\end{abstract}

\section{Keywords}

working paper, open access, academic collaboration

\section{Introduction}

Working papers are academic articles in various stages of completion, which represents a significant publication venue in various academic disciplines. Specifically, working papers can be works in progress, under submission, or forthcoming and are often freely circulated at a certain level within a specific academic community. These working versions are generally offered in the interest of personal and public scholarship: they serve to notify others in the same academic community that a person happens to be working on a particular problem, which opens up the work to a wide audience and furthers public dialogue. In addition, the authors of working papers often benefit from the diverse opinions brought by their audience due to the free circulation of these papers, which hones the ideas and concepts therein. There is no intrinsic reason not to cite working papers though they generally require an explicit versioning system and metadata to mark their progress and evolution. However, it is a good practice to cite the final papers if and when they are published.

The current article aims at offering a defense of working papers' academic values. For this purposes, we want to set aside the question regarding the practice and value of peer-review and the extent to which it validates and sanctions the quality of a paper's contents. We think it goes without saying that a working paper series can be peer-reviewed and it is certainly possible that they could be subjected to a more thorough peer-review process than some journal submissions ${ }^{1}$. The far more interesting issue is the institutional value placed on this kind of publication irrespective of reviewing practices ${ }^{2}$. Following a brief review of critiques regarding working papers as a form of 
academic publishing practice, the articles offers the article discusses their major benefits and argues in favour of their adoption by graduate students as valuable publishing practices.

\section{Misunderstandings of Working Papers}

There are three primary clusters of critiques regarding working papers: (1) the quality of working papers, (2) potential clashes between working papers and formal publications, and (3) limited readership of working papers.

\section{The quality of working papers}

The first common concern regarding working papers is their quality. It has been argued that working papers lack quality control, irrespective of the implementation of a rigorous review procedure. Working papers are regarded as performative rather than substantive. Being relatively easy to produce, they are likely to be used to satisfy grant donors, and give the "symbolic impression" of academic production rather than actually being academic production. According to the above critique, it would be better to invest the time in writing up an academic paper instead. Second, being less rigorous, working papers may create misleading impressions. This argument posits that, as their findings are provisional and most working papers could be improved, refined, or overturned, they can cause damage if the working papers are cited by those outside the university, such as policy makers or ideologues to further their interests. Third, there is a presumed risk that circulating working papers may bring about unforeseen negative consequence. Academic research is conducted for both epistemic and pragmatic purposes. But for papers with practical social or policy implications, findings need to be thoroughly evaluated to avoid potential repercussions outside the academy. Unfortunately, working papers often lend credibility and legitimacy to work that has not been validated, which may in turn lead to negative consequences.

To defuse the above concerns, we want to emphasize several key aspects of the practice of academic research. First of all, it needs to be kept in mind that the dissemination of iterations is crucial to improving work to the point where it might be publishable. It is very common for scholars to distribute unpublished manuscripts to colleagues for comments. Thus, disseminating working papers is complementary to the advancement of a project to publication. To the extent that scholarly publications are professional communications, it is right and proper that significant works be built up from smaller discussions.

Moreover, the burden of responsibility, we feel, rests with the reader to understand that the data and findings of working papers are provisional. For anyone who reads the research which inspires tabloids' "scientists say" screamers, the inescapable conclusion is that the only protection against having one's work misrepresented is to refuse to release it.

Finally, no single study should be taken to be definitive without adequate support (or at least we hope that no policy makers work this way). Even papers published in top journals may be overturned by follow-up studies. Those seeking to claim a working paper's finding as credible across a whole range of cases likely have interests other than scholarship (or good governance) at play. Although verification and replication may be the scientific ideal, scientific publishing leans

toward the novel and significant. The development of extra-journal repositories for such validating work is a recognized solution even in the most prestigious forums (Schooler, 2011; Nature Editorial, 2012).

The clashes between working papers and formal publications 
The second common concern regarding working papers is that they might obstruct further submissions as formal papers. This concern encompasses three perspectives. First, journals may rescind offers of publication. As there is a working paper version, journals might not see the value in publishing material that already exists online. This could impede professional advancement because the work is not published in a prestigious, designated venue. Second, working papers are "poor" first impressions of your work. Should you submit the paper to a journal, reviewers can easily find previous (weaker) versions - potentially negatively impacting your publication opportunities. This often goes by the name of a "continued influence effect of misinformation". Furthermore, due to the provisional nature of working papers, it is perhaps premature to make these findings public and people may remember the weaker working papers rather than the subsequent articles to which they might contribute. With these factors in mind, the question becomes: if people are to read only one version of the paper, which one would you prefer it to be? Third, working papers may cause iteration issues. Iterative working papers, like living policy documents, make retractions difficult. As a result of the nature of working papers, iterations are possible and it is difficult to pull back material that has been published especially in the digital age. As interpretations change or more data gathered is gathered, one can ask: what happens when findings radically alter? Working papers make retractions difficult because you cannot guarantee that newer versions will be read. Further, it is difficult to show which portions have changed from iteration to iteration.

To refute the above arguments, we want to draw attention to practices within the academic publishing industry. First, although some publishing venues may be reluctant to publish a paper if it has been circulating as a working paper, this is by no means an insurmountable problem, particularly as the majority if journals allow for some form of self-archiving. This means pre-prints can be placed in the institutional repository without it affecting publication prospects (Gutam, $2012)^{3}$. This generally stems from the fact that journal publishers, although perhaps not their editors, are primarily interested in bundling articles to sell to a library, as opposed to being interested in the status of any one particular article's iteration.

Moreover, the logic of "working papers are equal to weak publications" is problematic. This logic presumes that working papers are by nature weak; the publication of set components of a much larger paper need not be rough or poorly formed. What makes papers weak is the quality of the work within them, not their iteration. It is also quite possible to have working papers reviewed, but we think people are generally forgiving knowing that it is a working paper, and not a policy proposal, nor the mature work of a project. In terms of the first impression issue, while this is a concern, we think the circulation of a working paper is a testament to a researcher's character in that they are willing to admit and correct mistakes and that it will be through this lens that they are viewed. This line of argument holds the prevention of public confusion superior to the pursuit of knowledge and the truth which we believe to be an error. Indeed, transparency and engagement are far more likely to aid the pursuit of knowledge and truth than selective disclosure.

Finally, the critique regarding iterations is benign since working papers should not be taken as definitive, and to do so would be an error on the part of the reader, not the author. This criticism is more a legacy of paper media than strictly a feature of working papers, as it is a trivial matter to add retractions, modifications, versioning and change tracking to digital publications. A cover sheet highlighting version control and notification of which major sections have been improved can be attached, as is common practice among open source software developers. 


\section{The readership of working papers}

The final concern regarding working papers is their readership. The argument is: people don't thoroughly read working papers. Good comments take time and careful reading; however, most people do not read working papers at the level of depth required for provision of adequate feedback. Thus, working papers do not necessarily accomplish the aim of soliciting constructive feedback. This is certainly a strong argument against releasing immature and rough work. But this presumes an equivalency between working papers and immature projects. Working papers can indeed be well developed, yet are released in the interests of scholarship for others to comment upon. Here, we want to cite the example of MIT Working Papers in Linguistics, which enjoys an enormous readership due to a reputation built on the publication of quality works. Having addressed these three categorical criticisms, we hope that we have demonstrated how the above concerns (some valid and some less so) can be mitigated and managed.

\section{Benefits of Working Papers}

Having discussed a few common misunderstandings regarding working papers, it is time to address several key benefits they may offer. From our perspective, the benefits of working papers can be categorized into four themes: (1) they provide valuable feedback for work in progress; (2) they create potential opportunities for collaboration; (3) they have flexibility to allow various forms of dissemination; (4) they are valuable opportunities for intellectual development and capacity building, especially for young scholars and graduate students. Altogether, these benefits underscore a commitment to open-access research that is accessible to the public at large.

\section{Valuable feedback}

Working papers relay information as it evolves and becomes available. Compared with formal publications, working papers are amenable to constructive criticism and seek to evolve and improve. The feedback provided by readers can be used to polish arguments and refine thinking. As discussed in the previous section, there is value to iterative writing projects, and the publication and dissemination of smaller portions of the bigger project. Publication offers time for reflection and an evaluation of the project. This process is greatly facilitated if the working paper is deposited via a stable, digital venue. This also enables the author and/or editor to provide timely updates on their work. Furthermore, it is important to note that disclaimers can lay out the caveats to working papers, leaving it up to the user to decide on the utility of the information and appropriateness for their end use.

Moreover, working papers are useful because due to their transparent and provisional nature, errors can be detected and rectified where relevant, before the work is developed further. Transparency, in this case, is beneficial, and the provisional nature of working papers means that authors are likely to be amenable to and appreciative of such suggestions. This can reduce misimpressions and mistakes within subsequent work thereby further strengthening both the pieces themselves and the scholarly reputation of the authors.

\section{Opportunities for collaboration}

Another valuable aspect of working papers is that they offer outreach opportunities. Working papers help let others know what one is doing, expose work to non-traditional audiences, and to colleagues who work on similar but distinct problems. This can act as academic outreach: Informing others of your work in progress and expanding your academic network. This could promote 
opportunities for collaboration and input from colleagues who might not have seen the research otherwise. This can lead to opportunities a person might not expect, nor otherwise consider.

\section{The advantages of flexibility}

Compared with formal publications, working papers have several advantages in terms of flexibility. First, working papers release potentially useful information. In our minds, the costs of publicationchill and restricting partially complete information and knowledge that otherwise might help others are far too high for a healthy academic public sphere. In this vein, it is useful for working papers to outline transparent standards so that readers may better understand the expectations surrounding working papers.

\section{The benefits for intellectual development}

Publishing working papers is a great way to encourage writing. In particular, for young scholars such as graduate students, writing working papers can help you drive towards preliminary drafts, and can prompt people to write more. When mired in the joys of research, deadlines force a researcher to commit thoughts to paper - and writing is a reflective exercise which brings coherence to thought.

Writing working papers is a capacity-building process as well which informs wider intellectual development. Particularly for master students who decide not to pursue a professional academic career, circulating their results in a working paper format may be an end in itself. It makes the degree less a project of the self, and more about disseminating research. Lastly, it helps graduate students demystify the review and revision process, giving them confidence to submit subsequently to other venues.

\section{The commitment to accessibility}

Altogether, the aforementioned points speak to a wider project of making academic work accessible. Many undergraduates, graduates, and academics in developing countries face difficulties accessing research due to the increasing subscription fees and pay-walls of large publication corporations such as Sage, Elsevier, and Routledge. Martin Weller, an education researcher, when speaking of open access explains the implications this development. He writes that:

"Open access allows for a new life for articles, for them to be taken, republished in different collections or reused in different contexts. This can happen with existing, propriety articles but it's a closed process, and it is open access that allows for the generative, innovative reuse that will allow articles to be reclaimed".

$$
\text { Martin Weller (2011, para. 2) }
$$

Weller's point about open access applies as much to working papers: It is an effort to make the work available to those who otherwise might not be able to access it.

\section{Successful Cases}

We can point to several famous working paper series. The stencilled working paper series by the Center for Contemporary Cultural Studies (CCCS), comes from the field of communication studies. Now it is almost impossible for students in communications studies not to encounter Stuart Hall's "Encoding and Decoding", originally published as a working paper by CCCS. As another example consider that one of the founding pieces of scholarship for social network analysis: Pool and 
Kochen's Contacts and Influence (1979) was circulated as a working paper for over two decades before it was published in the first issue of Social Networks. As Freeman, Mitchell, and Ziegler (1979) note, since the 1950s when it was written the manuscript became so widely circulated, and so generative for other scholars, that it helped the formation of a new field. It was eventually published, unfinished, because it had become a foundational text without itself being submitted for peer review.

There are also benefits to a simple pre-print repository. Consider ArXiv.org, a preprint archive for natural science papers which has been around for more than twenty years. The papers uploaded in this repository are not peer-reviewed, the only requirement being that the paper be "in principle suitable for review". Indeed, ArXiv has been so successful that Sir Martin Rees suggests that it has:

"Transformed the literature of physics, establishing a new model for communication over the whole of science. Far fewer people today read traditional journals. These have so far survived as guarantors of quality. But even this role may soon be trumped by a more informal system of quality control, signaled by the approbation of discerning readers".

Rees (2010, para. 6)

Within social sciences, the Social Science Research Network (SSRN) fulfills a similar function. To conclude, for the reasons outlined, we believe we have offered a reasonable defence of working papers. In this defence we view working papers to a convenient and inviting place to publish interim findings while maintaining an academic standard. In this manner working papers can cater to a specific variety of scholarship that enables skill creation and enriches the public realm.

\section{Notes}

1. While there are legitimate criticisms to be made of the practice of peer review it remains one of the best methods for filtering out naked commercial and public relations influences while encouraging communal editorial control. For instance, MIT Working Papers in Linguistics, which publishes working hypothesis in the field of Linguistics, have a rigorous peer-review process and is regarded as one of the top journals in its field. Similarly, we will not discuss issues regarding data collection and analysis methods since such issues are more relevant to disciplinary practices than the type of publications.

2. Interested readers may wish to consult this working paper: "Is Peer Review in Decline?" http://econ-www.mit.edu/faculty/gellison/papers.

3. We are indebted to Heather Morrison for this point.

\section{References}

Freeman L. C., Mitchell, J. C., and Ziegler, R. (1979). Editorial. Social Networks 1(1), 1-3.

Gutam, S. (2012, December). When 67\% of publishers allow some form of self-archiving. Open Access India, Retrieved from http://oaindia2013.wordpress.com/2012/12/27/when-67-ofpublishers-allow-some-form-of-self-archiving/

Nature Editorial (2012, October). Repeat after me, Nature Medicine, 18, 1443. Retrieved from http://www.nature.com/nm/journal/v18/n10/full/nm.2978.html

Pool, I. de S., \& Kochen, M. (1979). Contacts and influence. Social Networks, 1(1), 5-51.

Rees, M. (2010, December). A level playing field. Edge.org. Retrieved from http://edge.org/q2010/q10_2.html\#rees

Schooler, J. (2011, Feburary). Unpublished results hide the decline effect. Nature, 470, 437. Retrieved from http://www.nature.com/news/2011/110223/full/470437a.html 
Timcke et al.

Weller, M. (2011, December). The ghost of Christmases past, present and future come bearing lessons of academic publishing. The Impact of Social Sciences Project. Retrieved from http://blogs.lse.ac.uk/impactofsocialsciences/2011/12/23/the-ghosts-of-christmases-pastpresent-and-future-come-bearing-lessons-of-academic-publishing/ 